\title{
EXPERIMENTAL BOTRYOMYCOSIS PRODUCED BY PSEUDOMONAS AERUGINOSA
}

\author{
J. E. Mackinnon, I. A. Conti-Díaz, E. Gezuele, J. Galiana, \\ C. Hormaeche and E. Civila \\ Instituto de Higiene, Facultad de Medicina, Montevideo, Uruguay
}

\section{Plate XXIX}

IN a continuing study on the habitat of the agents of deep mycoses, suspensions of soil and plant debris are injected into guinea-pigs and mice. Several moulds and actinomycetes have been observed in, or cultivated from, lesions produced in the experimental animal or their apparently normal tissues. During this work we observed that Pseudomonas aeruginosa (Ps. pyocyanea) may produce actinomycetoid granules and the histopathological picture of botryomycosis.

\section{MATERIALS AND METHODS}

Our first observations were accidental. If our purpose had been to isolate Ps. aeruginosa we should not have used the method described below, which is a modification of that of Emmons (1949). Seventy-four samples of soil and 51 of plant debris were taken with sterile wooden tongue-depressors and placed in plastic bags. The samples of plant debris included 24 samples of powdery or fibrous debris from rotten palm-tree trunks, 8 nests of armadillos and wild rodents, built up with grass blades, and 19 samples taken from hollows in tree trunks.

A $5-\mathrm{ml}$ volume of each material was placed in a sterile flask with $25 \mathrm{ml}$ isotonic saline solution and glass beads and shaken vigorously for $5 \mathrm{~min}$. The suspension was then left for 5-10 min.; heavy particles settled and the plant debris floated. An 8-ml volume of the intervening small-particle suspension was pipetted into a test-tube with $2 \mathrm{ml}$ of a solution containing $5 \mathrm{mg}$ penicillin and $4 \mathrm{mg}$ dihydrostreptomycin per $\mathrm{ml}$. Guinea-pigs received $0.2 \mathrm{ml}$ of this suspension in each testicle, and male mice were given $0.25-\mathrm{ml}$ doses intraperitoneally.

The exudates from the lesions produced in these animals were examined in stained smears and also in wet preparations directly between slide and coverslip. Sections from tissues fixed in 4 per cent. formaldehyde and embedded in paraffin were stained with haematoxylin and eosin.

The following results refer to observations and experiments with 3 strains of Ps. aeruginosa; 2 were isolated from plant debris and 1 strain was isolated from man.

\section{RESULTS}

\section{Experiments with the first strain isolated from plant debris}

The inoculated material was taken from the decayed trunk of a fallen palm-tree (Butia yatay) of which the inner portion was soft, spongy and at some areas hollow. Skunks, armadillos and small wild rodents had penetrated and some had made their nests with grass. Larvae of beetles, ants and other arthropods were found.

After intratesticular injection of the sample, the test guinea-pig showed bilateral orchitis; the animal was killed 20 days after the inoculation. Filaments of a semi-acid-fast actinomycete were seen in the exudate from the left testicle; granules were not found, but cultures yielded Nocardia brasiliensis. Actinomycetoid granules with clubs were seen in the pus of the right testicle when examined between slide and coverslip; filaments of actinomycetes were not seen; a Gram-negative bacillus was seen in smears, and culture produced a growth of 
$N$. brasiliensis on Sabouraud glucose agar and Ps. aeruginosa on the same medium and on brain-heart infusion agar. The granules showed a shell which is not seen in those produced by nocardiae. The guinea-pig also had small abscesses in the lungs with actinomycetoid granules and Ps. aeruginosa was the only organism cultured from these lesions. In tissuesections of the right testicle and lungs we saw actinomycetoid granules up to $100 \mu \mathrm{m}$ in diameter; they showed eosinophilic clubs inserted on an eosinophilic shell which encloses the central portion of the granules (figs. 1 and 2).

After checking the purity of the cultures of Ps. aeruginosa, we injected the strain intratesticularly into 2 guinea-pigs: 1 animal received $0.2 \mathrm{ml}$ of an opalescent suspension of a 24-hr culture grown at $37^{\circ} \mathrm{C}$ on brain-heart infusion agar; the guinea-pig was dead $18 \mathrm{hr}$ later and showed haemorrhagic lesions without granules. A second guinea-pig, given a smaller dose of an old culture, survived for 4 days and developed orchitis and pulmonary abscesses with actinomycetoid granules.

\section{Experiments with the second strain from plant debris}

The inoculated material was similar to that previously described. No lesions were recorded in the first test guinea-pig in this series. Five mice were killed 42 days after intraperitoneal inoculation of the material. Two mice showed abscesses of the liver with clumps of a Gram-negative bacillus, but no granules were seen. Cultures prepared from the liver abscesses yielded Ps. aeruginosa.

Guinea-pigs were given 0.1-ml intratesticular injections of graded doses of Ps. aeruginosa. A dose of a suspension containing $10^{2}$ bacteria per $\mathrm{ml}$ did not produce orchitis. A similar injection of a suspension containing $10^{4}$ bacteria per $\mathrm{ml}$ produced a nodule measuring $1 \mathrm{~cm}$ in diameter when the guinea-pig was killed 23 days after the inoculation. Granules measuring up to $300 \mu \mathrm{m}$ in diameter were seen in the pus between slide and coverslip and Ps. aeruginosa was recovered from cultures. A $0 \cdot 1-\mathrm{ml}$ dose of a suspension containing $10^{6}$ bacteria per $\mathrm{ml}$ produced an acute inflammatory process; the guinea-pig was dying 5 days after the inoculation and was killed. Typical granules with clubs were seen and Ps. aeruginosa was recovered from cultures.

The same suspensions were inoculated intraperitoneally into mice in doses of $0.2 \mathrm{ml}$. Suspensions containing $10^{2}$ and $10^{4}$ bacteria per $\mathrm{ml}$ did not produce lesions in the 5 mice challenged in each series. A suspension of $10^{6}$ bacteria per $\mathrm{ml}$ was inoculated into 4 mice and produced the following results: 1 mouse died 8 days after the inoculation with abscesses in the cortical zones and in the pelves of the kidneys; no granules were seen, but Ps. aeruginosa was recovered in cultures. The other 3 mice were killed 44 days after the inoculation and 1 of them showed a small abscess in the omentum without granules.

\section{Experiments with a strain isolated from man}

A strain of Ps. aeruginosa was isolated from a human case of otitis media. Two guineapigs were challenged intratesticularly with $0.1 \mathrm{ml}$ of a suspension of this strain containing $10^{4}$ bacteria per $\mathrm{ml}$. One animal showed orchitis and was killed 14 days after the inoculation. Actinomycetoid granules with the typical clubs and shells were seen in the pus between slide and coverslip and in stained tissue-sections. Ps. aeruginosa was recovered in cultures. The second guinea-pig was killed 30 days after the inoculation: no lesions were found.

\section{Discussion}

Several species of non-filamentous schizomycetes may provoke granules with eosinophilic clubs when they infect animal tissues. Our experiments indicate that Ps. aeruginosa may provoke the formation of granules, and it is of interest that Winslow and Chamblin (1960) suspected that this species was the agent in a human case of visceral disseminated botryomycosis.

Aynaud (1928) considered that botryomycosis would probably be much more frequently recorded if direct examination between slide and coverslip were regularly practised; the 
BOTRYOMYCOSIS PRODUCED BY PSEUDOMONAS

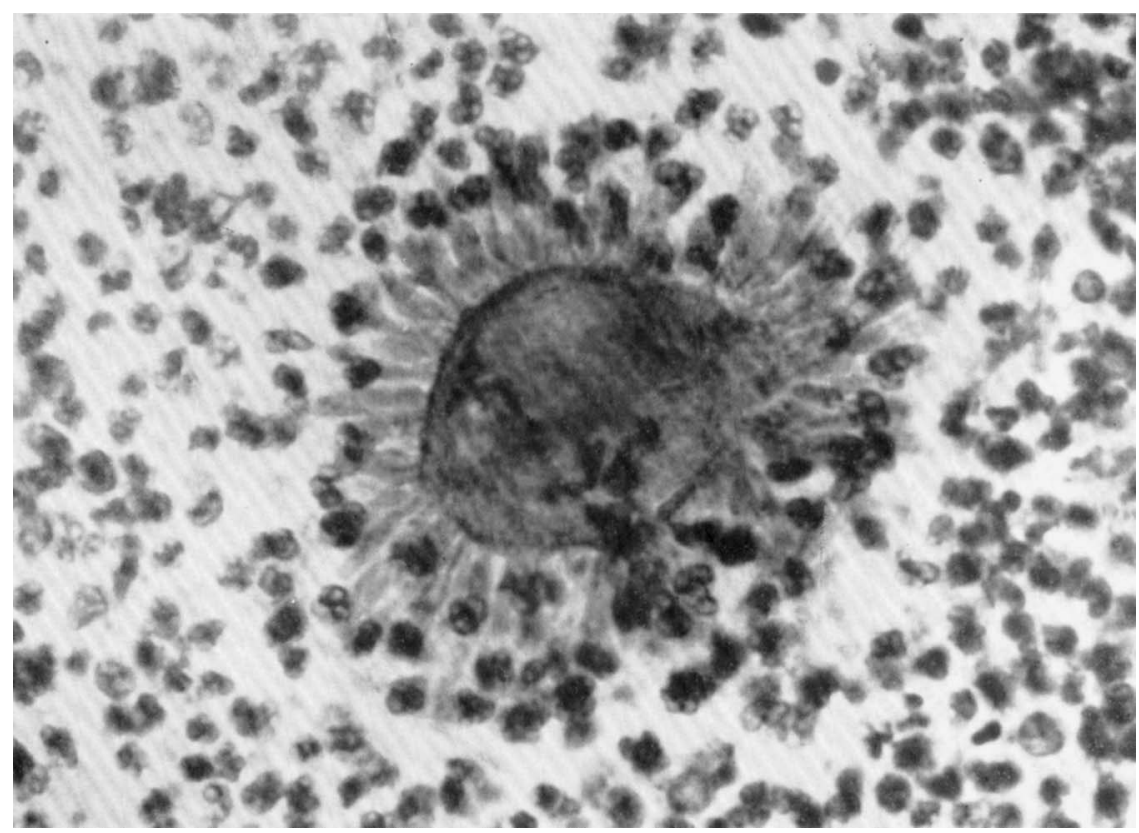

FIG. 1.-Granule associated with Pseudomonas aeruginosa infection in tissue-section of testicle of guinea-pig. Haematoxylin and eosin (HE). $\times 900$.

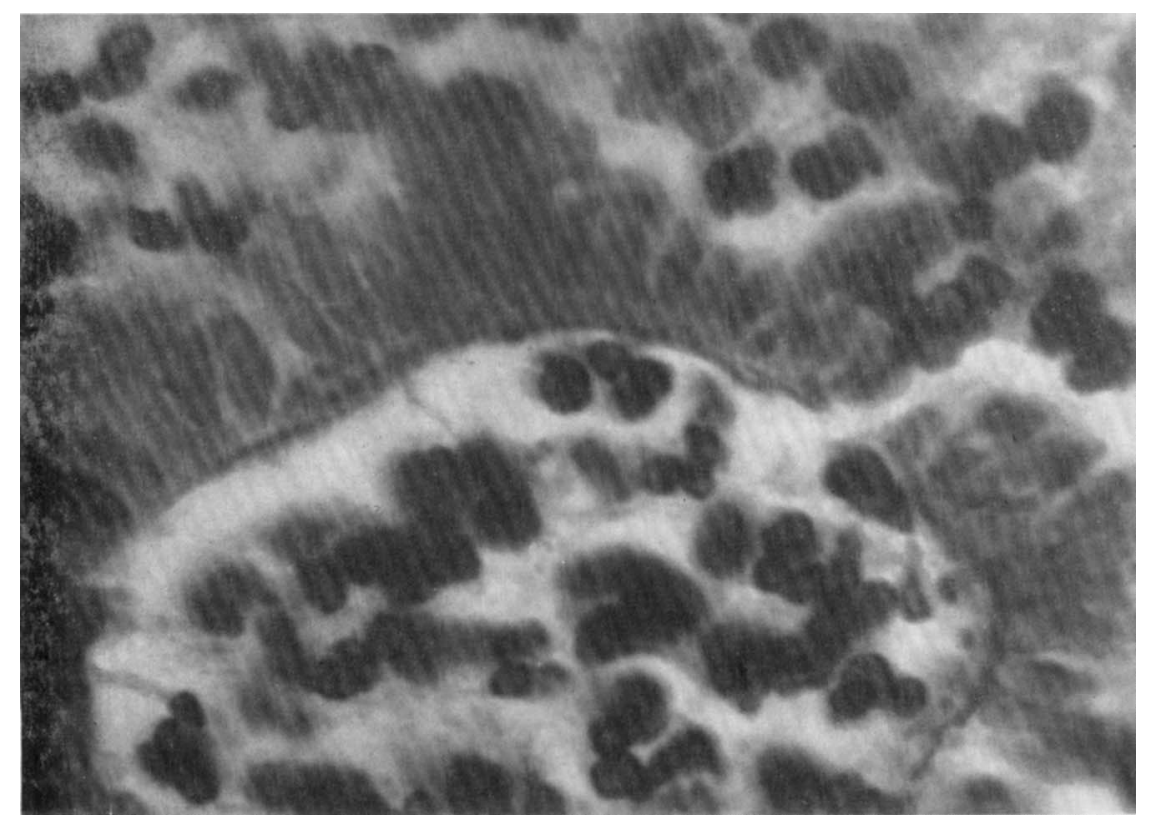

FIG. 2.-Granule associated with Ps. aeruginosa infection in the lung of guinea-pig. Metastatic abscess. HE. $\times 1500$. 
granules are destroyed in smears. On the other hand, Winslow (1959) noted that histopathological studies revealed that 6 cases of botryomycosis had been considered to be cases of nocardiosis, mycetoma, actinomycosis or Madura foot. In other words, when tissuesections or wet preparations of exudate between slide and coverslip are not examined, the granules are missed; moreover, when the granules are found in tissue-sections, they are attributed almost always to fungi and actinomycetes. Consequently, botryomycosis usually escapes recognition.

Magrou (1919) believed that the development of granules depends both on the virulence of the micro-organism, a staphylococcus in his study, and on the resistance of the host, and that a special balance is necessary. Winslow and Chamblin expressed similar ideas and thought that the administration of antibiotics may have an influence on natural balances with the result that some bacteria that usually do not produce botryomycotic lesions could do so.

Foreign bodies may play a role in the production of botryomycotic lesions according to some authors (Magrou; Plaut, 1937; Kimmelstiel and Easley, 1940), but Magrou believed that they are not necessary; they have not been intentionally introduced in our own experiments. The dead mycelium of an actinomycete may elicit the formation of eosinophilic clubs in the guinea-pig (Meyer, 1934).

Differences exist between the granules produced by Streptomyces madurae, S. somaliensis and $S$. pelletieri, which are also different from those produced by species of the genus Nocardia (Mackinnon and Artagaveytia-Allende, 1956). The granules produced in response to $P$ s. aeruginosa are also quite distinctive and show an eosinophilic shell with eosinophilic clubs inserted on the outer surface, as perhaps do granules produced by some other eubacteria. Magrou noted the existence of such a shell and in some drawings a membranous structure is shown that is like the structure we saw. The coexistence of an eosinophilic shell and clubs is a noteworthy characteristic; a membrane or shell exists in granules produced by $S$. pelletieri, but clubs are not produced.

Mariat and Drouhet (1954) pointed out the similarities in shape and size of the eosinophilic clubs produced around quite different organisms. Pine and Overman (1963) considered that the clubs of the granules produced by Actinomyces bovis are capsules surrounding the hyphae. This is an interesting view, but if we generalise it we should be obliged to admit that within each club of the asteroides form of Sporothrix schenckii, Candida albicans and other fungi there exists a mycelial element. This conclusion is not compatible with accepted views on the normal structure of the fungi.

It may be argued that our finding of clubs and shells in lesions associated with $P$ s. aeruginosa suggests that the bacterial infection may have stimulated a host response to a latent fungal infection in the experimental animal. The unusual morphology of the granules observed in our studies, the absence of mycelial elements in the smears and our inability to isolate fungi from the lesions produced after inoculation of pure cultures of Ps. aeruginosa provide good evidence that fungi and actinomycetes are not involved. Moreover, our findings lend support to the view that the development of structures characteristic of actinomycetoid granules with clubs and shells is dependent upon a host response although the infecting agent appears to influence their architecture.

\section{SUMMARY}

Guinea-pigs intratesticularly challenged with small doses of Pseudomonas aeruginosa developed local abscesses with actinomycetoid granules measuring up to $300 \mu \mathrm{m}$ in diameter; metastatic foci of infection in the lungs also contained granules. An eosinophilic shell supporting a crown of eosinophilic clubs is a noteworthy characteristic of the young granules produced by all three of the strains of Ps. aeruginosa studied. Granules were visible as early as 4 days after the inoculation of $0 \cdot 1-\mathrm{ml}$ doses of suspensions containing $10^{4}$ bacteria per $\mathrm{ml}$. No granules were produced in the mice challenged intraperitoneally.

Two of the test strains of Ps. aeruginosa were isolated from plant debris accessible to wild animals, insects and other arthropods. The third strain was isolated from a human case of otitis media. 
The observations recorded in this article were made during the development of a research project supported by the Universidad de la Republica, Uruguay, and by the United States Army.

The authors are indebted to Dr Marfa L. Iraola de Toledo for histopathological facilities and to Mr R. Cesarco for the photographic work.

\title{
REFERENCES
}

Aynaud, M. . . . . . . . . 1928. Annls Inst. Pasteur, Paris, 42, 256.

EMmons, C. W. . . . . . . . . . . 1949. Publ. Hlth Rep., Wash., 64, 892.

Kimmelstiel, P., and Easley, C. A., Jr . 1940. Amer. J. Path., 16, 95.

Mackinnon, J. E., and Artagaveytia- 1956. Trans. Roy. Soc. Trop. Med. Hyg., 50,

Allende, R. C. 31.

Magrou, J. . . . . . . . . . 1919. Annls Inst. Pasteur, Paris, 33, 344.

Mariat, F., AND DROUhet, E. . . . 1954. Ibid., 86, 485.

Meyer, K. . . . . . . . . . 1934. C.r. Séanc. Soc. Biol., 115, 1684.

Pine, L., AND Overman, J. R. . . . 1963. J. Gen. Microbiol., 32, 209.

Plaut, A. . . . . . . . . . 1937. Archs Path., 23, 602.

Winslow, D. J. . . . . . . . . 1959. Amer. J. Path., 35, 153.

Winslow, D. J., and Chamblin, S. A. . 1960. Amer. J. Clin. Path., 33, 43.

\section{RELAPSE OF URINARY TRACT INFECTION IN THE PRESENCE OF URINARY TRACT CALCULI: THE ROLE OF BACTERIA WITHIN THE CALCULI}

\author{
H. Rocha AND L. C. S. SANTos \\ Department of Medicine, University of Bahia, Salvador, Bahia, Brazil
}

THE association between infection of the urinary tract and urinary calculi is well known and has been documented for many years (Harris, 1900; Vermeulen, 1960). Calculi enhance the susceptibility of the urinary tract to infection (Vermeulen; Rocha and de Almeida, 1965), and infection can predispose to stone formation (Harris; Vermeulen).

Attempts to sterilise an infected urinary tract in the presence of stones almost always meet with failure (Lindemeyer, Turck and Petersdorf, 1963). Relapse or reinfection is the rule under these circumstances and this suggests that calculi may serve as a nidus of infection in which bacteria are protected from the action of antimicrobial drugs.

The purpose of the present study was to determine whether bacteria within urinary calculi remain viable in spite of exposure to antibacterial drugs, and whether bacteria within a calculus can infect surrounding culture media.

\section{MATERIALS AND METHODS}

Bladder calculi from 6 patients, admitted to Hospital Prof. Edgard Santos, were collected under sterile conditions at time of surgery. Quantitative urine cultures were performed in all patients before surgery and at the time of the removal of calculi. Two patients (cases no. 1 and 6) had 2 calculi in the urinary bladder. The calculi from patients no. 2, 3, 4, 5 and 6 were put into a 3 per cent. solution of iodine in absolute alcohol for periods of 2-6 hr, after which they were washed twenty times, each time in about $50 \mathrm{ml}$ sterile distilled water. The last portion of distilled water in contact with the calculus was cultured by inoculating $1 \mathrm{ml}$ into $9 \mathrm{ml}$ of trypticase soy broth (Baltimore Biological Laboratories), and also by direct streaking with a platinum loop on to the surface of a blood agar plate subsequently incubated 